\title{
Investigation of wear of insulation of traction engines of locomotives in operation
}

\author{
Roman Nefedov ${ }^{1}$ and Elena Loginova ${ }^{2,3, *}$ \\ ${ }^{1}$ Russian Railwas (RZD) Moscow, Russia \\ ${ }^{2}$ Moscow Technological Institute, Moscow, Russia \\ ${ }^{3}$ Russian University of Transport (MIIT), Moscow, Russia
}

\begin{abstract}
The article analyzes reliability of traction electric motors in operation. It is shown that the greatest number of failure falls on the winding of the armature. Investigation of the causes of increased wear of the armature winding insulation was carried out using the dynamic thermal model of the electric motor. The model is represented by 150 final elements and takes into account the conditions of thermal conductivity between the nodes and heat transfer to the cooling air. Verification of the model was carried out by comparison with the results of thermal tests of electric motors of the series НБ-406 and ЭД- 118 . Тhe field of temperatures in the traction motor under various loads was investigated. It is shown that in stationary mode the temperature change along the armature winding can reach $60 \mathrm{C}$. Modeling of thermal dynamic processes in the engine during its operation on the locomotive allowed to identify the most stressed nodes. It is shown that the resource of the electric motor is determined by the wear of the insulation of the frontal part of the armature winding on the side of the traction drive of the locomotive.
\end{abstract}

\section{Introduction}

The traction electric motor is the main aggregate of the power chain of the locomotive. Its reliability determines the reliability of the entire locomotive [1]. The manufacturer determines the planned mileage of traction motors $1.2 \mathrm{mln} \mathrm{km}$. But in practice the mileage of traction motors is much smaller. The experience of the depot Gorkovskoye showed that the maximum value of the failure flow of traction engines corresponds to a mileage of $0.42 \mathrm{mln} \mathrm{km} \mathrm{(Fig.} \mathrm{1)} \mathrm{[2].} \mathrm{The} \mathrm{main} \mathrm{flow} \mathrm{of}$ failures occurs at the motor armature (Fig. 2) [3].

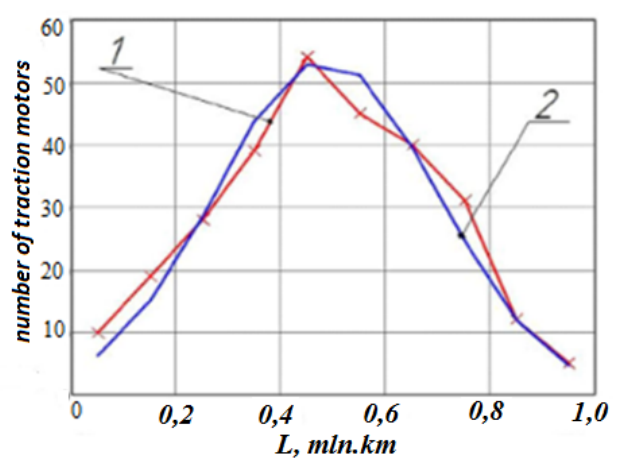

Fig. 1. The failure flowof traction engines of lokomotives in 2011-2012: 1- experimental data; 2 - theoretical curve of the normal distribution

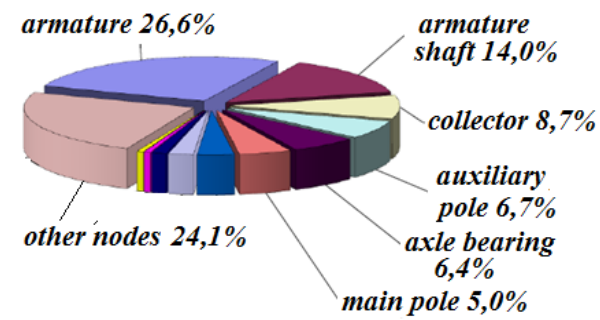

Fig. 2. Malfunctions of traction electric motors of ED118 in 2014.

\section{Study and modelling}

To study the processes in the traction motor was created its dynamic thermal model. The model is represented by 150 final elements and takes into account the conditions of thermal conductivity between the nodes and heat transfer to the cooling air.

The basis of the model consists of differential equations of the form:

$$
\frac{d T_{k}}{d \tau}=\sum_{l=1}^{b} \alpha_{k l}\left(T_{k}, T_{l}\right) \cdot\left(T_{k}-T_{l}\right)+\sum_{k=1}^{m} W_{k}\left(T_{k}\right)
$$

where $\quad \alpha_{k l}\left(T_{k}, T_{l}\right)=\Lambda_{k l}\left(T_{k}, T_{l}\right) / C_{k}\left(T_{k}\right), \quad W_{k}\left(T_{k}\right)=P_{k}\left(T_{k}, \tau\right) / C_{k}\left(T_{k}\right)-$ parameters of adiabatic heating of the k-th node, due to heat transfer to the heat carrier and heat exchange with adjacent nodes of the machine; $\Lambda_{k l}\left(T_{k}, T_{l}\right)$ - coefficients of the heat transfer matrix from the $k$-th node to the heat carrier and thermal radiations; $C_{k}\left(T_{k}\right)$ - reduced heat capacity of the $k$-th node. 
The model of aerodynamic processes in the electric motor was represented by a discrete system of distribution of air flows through cooling channels. The collector channels of the cooling system were represented $\left(\mathrm{n}_{1}+\mathrm{n}_{2}\right)$ by discrete sections with aerodynamic tees, where $\mathrm{n} 1$ and $\mathrm{n} 2$ are the number of tees to the right and left of the collector along the course of the airflow. The aerodynamic model had a nonlinear formulation. The aerodynamic resistance of the cooling system was determined by the value of the air speed taking into account the effect of rotation of the air ducts of the armature [2-3].

Comparison of the calculated and experimental temperature field in the armature winding НБ-406 showed their good convergence (Fig. 3).

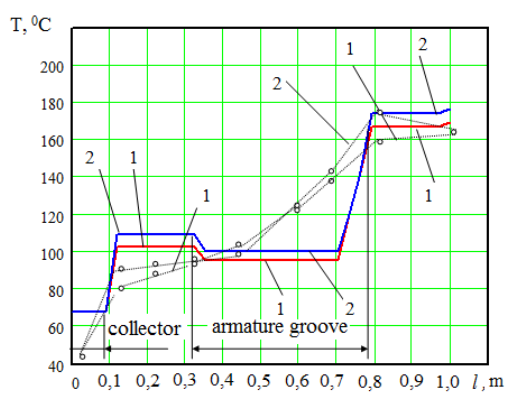

Fig. 3. Temperature distribution in the winding of the motor armature of the НБ-406 in the rated operating mode.

The error in calculating the heating curves of the armature winding at the rated power of the traction motor did not exceed $7 \%$ for the whole range of the load current (Fig. 4). To calculate the steady-state temperature distribution in the windings of the electric motor, we used the model of its thermal state, in which the left-hand sides of all the differential equations (1) vanish.

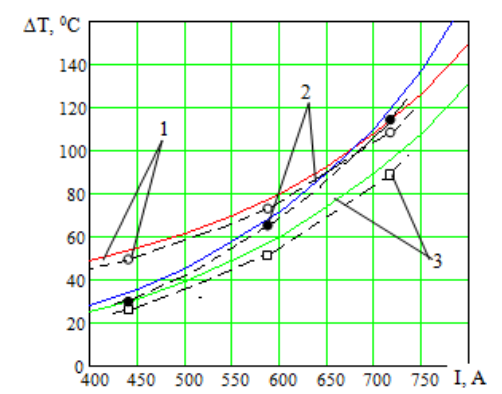

Fig. 4. The calculated (__ ) and experimental (- -) dependences of the excess of the mean temperature of the armature windings (1), the main poles (2), the additional poles (3) on the load current ED118A for the continuous operation mode and $t_{\mathrm{HB}}=260$.

The calculation of the mode of motion of the locomotive 2TE116 for the given section was carried out taking into account the kinetic energy of the train. The basis of the model was the traction characteristic of the locomotive at various operating modes of the power plant and the modes of weakening excitation of traction motors (Fig. 5).

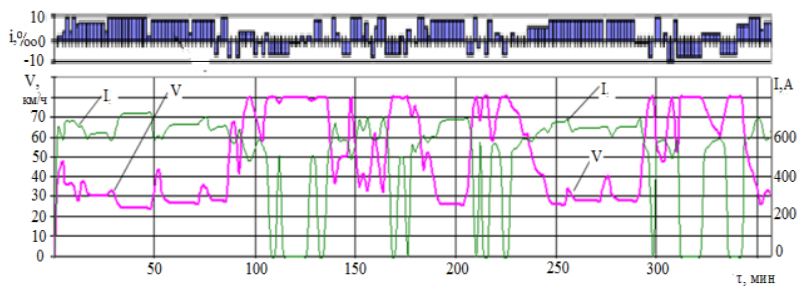

Fig. 5. Simulation of the movement of the diesel locomotive 2TЭ116 with the composition of the estimated weight for the section of the railway of the type III: i - the current slope value, $\mathrm{V}$ - train speed; I - traction motor current.

When modeling traffic processes at a train speed of $80 \mathrm{~km} \mathrm{/} \mathrm{h} \mathrm{(speed} \mathrm{limit} \mathrm{of} \mathrm{freight} \mathrm{cars),} \mathrm{the} \mathrm{diesel}$ generator was switched to idling. The air consumption for cooling the traction motors was set in accordance with the condition of the problem being solved.

When modeling the resource tests of traction motors on the thermal factor and the search for rational principles of cooling control, methods of non-linear programming, in particular, variational methods, were used.

All software modules for calculating non-stationary thermal processes of traction motors, including for calculating the values of cooling management evaluation criteria, are developed for Windows in the Borland $\mathrm{C}++$ integrated environment with the organization of streaming input / output of source data in the Microsoft Excel.

When solving management tasks related to operating modes of locomotives, a minimax approach was used to select traction engine loading regimes and a stochastic approach to account for operating conditions.

To calculate the insulation of the winding of the traction motor under various operating conditions and the selection of the cooling modes, the traction motor model as a non-stationary object is used, supplemented with a traction problem solution module, winding insulation wear calculation modules, and energy costs for cooling the engine.

Wear of insulation by thermal factor is defined as a value that is inverse to the insulation resource at a given temperature:

$$
q=\frac{1}{L(\Theta)}=\frac{1}{A} \cdot e^{-((B / \Theta)-G)},
$$

where $L(\Theta)$ is the resource insulation by thermal factor; $A, B, G$ - coefficients characterizing the properties of the insulating material; $\Theta$ - value of the absolute temperature of the winding.

Or when going to discrete welsh:

$$
q=\sum_{i=1}^{n} \frac{q_{i} \cdot \Delta \tau}{\tau}=\sum_{i=1}^{n} \frac{1}{\tau} \cdot \frac{1}{A} \cdot e^{-((B / \Theta)-G)} \cdot \Delta \tau,
$$

where $\Delta \tau$ is the integration step; $\tau$ is the current time. The results of modeling the temperature of the windings of traction motors during the movement of the locomotive by profiles of different types showed that with the full use of the power system's power, the armature winding has the greatest temperature throughout the entire driving regime (Fig. 6, 7). 


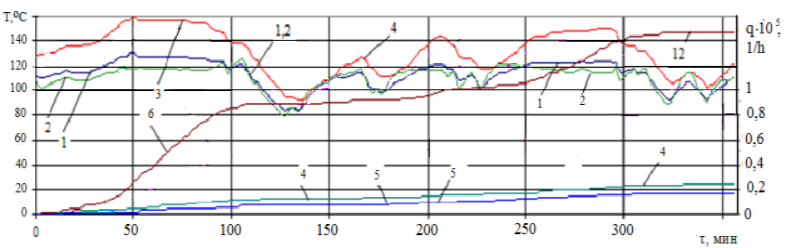

Fig. 6. The Changes of temperature of windings, wears insulation and energy consumption for cooling of winding ЭД118A operating in the energy circuit of the diesel locomotive 2ТЭ116 while moving along the III type profile with full use of the power at the outdoor air temperature of 25 $\mathrm{C}: 1$ ) average temperature of armature winding; 2) temperature winding of the armature in groove; 3 ) temperature of the front part of the armature winding from the drive side; 4) wear of the armature winding, determined by the average temperature of the winding; 5) wear of the armature winding, determined by the temperature of the groove; 6 - wear of armature winding, determined by the temperature of the frontal part.

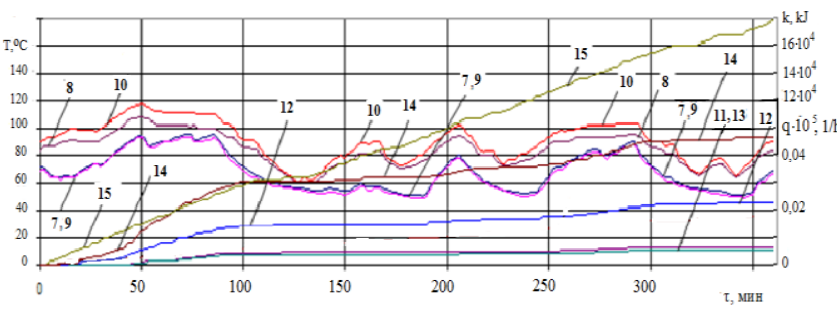

Fig. 7. The Changes of temperature of windings, wears insulation and energy consumption for cooling of winding ЭД118A operating in the energy circuit of the diesel locomotive 2ТЭ116 while moving along the III type profile with full use of the power at the outdoor air temperature of $25 \mathrm{C}: 7)$ average temperature of the winding of the main pole; 8) average temperature of the winding of the additional pole; 9) temperature of the middle part of the winding of the main pole, 10) temperature of the middle part of the winding of the additional pole; 11) wear of the winding of the main pole determined by the average temperature; 12) wear of the winding of the additional pole determined by the mean temperature; 13) wear of the winding of the main pole determined by the temperature of the middle part; 14) wear of the winding of the additional pole determined by the temperature of the middle part; 15) energy consumption for cooling the engine.

\section{Conclusions}

The average temperature of the armature winding only approximately shows the process of temperature variation of its individual nodes.

The actual temperatures of the elementary units of the armature winding during the operation of traction motors on unsteady conditions may differ from the average value by $10 \ldots 30 \mathrm{C}$.

The frontal part of the armature winding on the drive side always have of the maximum temperature $\left(t_{\mathrm{YK}}^{\mathrm{LP}}\right)$.

Therefore, the actual wear of the insulation of the frontal parts of the armature winding from the drive $q_{\mathrm{YK}}^{\mathrm{LP}}$ is $3 . .5$ times greater than the wear of the winding $q_{\mathrm{YKSR}}$ determined by the average temperature. This result is in good agreement with the operation data (Fig. 1).

The actual wear of the insulation of the coils of the main and additional poles by the thermal factor is almost 10 times less than the wear of the armature winding insulation.

Obviously, the frontal part of the armature winding on the drive side will determine resource of insulation of the traction motor in operation.

\section{References}

1. E.Y. Loginova, Buren-Itgel Gantumur, Cloud of science 2, 89 (2015)

2. 1.R. Nefedov, E. Loginova, Analysis of reliability of traction electric motors of locomotives, In Proceedings of the XVIth Scientific and Practical Conference "Safety of Train Traffic", pp. II-94-II-95 (2016)

3. O. Podlesy, E. Zenina, Bulletin of Volgograd State University. Series 10: Innovative activity, 2, 149 (2013) 